\title{
LOS ORÍGENES DE LA MORAL EN MENCIO Y EN HUME. UN ENSAYO DE FILOSOFÍA COMPARADA
}

\author{
THE ORIGINS OF MORALITY IN MENCIUS \\ AND HUME. AN ESSAY IN COMPARATIVE \\ PHILOSOPHY
}

\author{
Gerardo LÓPEZ SASTRE* \\ UNIVERSIDAD DE CASTILLA-LA MANCHA
}

Resumen: En este artículo vamos a intentar comprender el origen de la moral y cómo es que los seres humanos somos morales por naturaleza. Veremos que Mencio y Hume coinciden en afirmar que poseemos un sentimiento original de benevolencia o humanidad que se desarrolla o se corrige gracias a la imaginación y el razonamiento.

Palabras clave: Hume, Mencio, Filosofía comparada, Psicología moral, Ética.

Aвstract: In this article we will try to understand the origin of morality and how human beings are moral by nature. We will see that Mencius and Hume coincide in affirming that we have an original feeling of benevolence or humanity that can be developed or corrected thanks to imagination and reasoning.

Keywords: Hume, Mencius, Comparative Philosophy, Moral psychology, Ethics.

* Catedrático de Filosofía de la UCLM. Email: Gerardo.Lopez@uclm.es 


\section{Introducción. Las dotes morales de los humanos}

Nos gustaría defender que Mencio, un antiguo filósofo chino, elaboró unas ideas que resultan sorprendentemente actuales y que se prestan fácilmente a la comparación con determinadas teorías sobresalientes en el pensamiento occidental. Admitiendo que Mencio seguramente resultará poco conocido para muchos de los lectores de este artículo parece conveniente comenzar con un desvío que en su momento nos pueda hacer conscientes de su importancia. Por ello vamos a empezar enumerando lo que parecen ser los resultados que nos ofrece la psicología del desarrollo infantil sobre el ámbito de la moral. Un buen resumen se encuentra en el libro Just Babies. The Origins of Good and Evil del profesor de psicología de la Universidad de Yale Paul Bloom. A través de múltiples observaciones y experimentos este psicólogo prueba de una manera completamente convincente que algunos aspectos de la moralidad están de forma natural dentro de nosotros ya desde la infancia. Nuestras dotes naturales incluyen:

1.- Un sentido moral, cierta capacidad para distinguir entre las acciones crueles y las que podemos llamar amables.

2.- La empatía y la compasión, la capacidad de sufrir ante el dolor de los que nos rodean y el deseo de que ese dolor desaparezca.

3.- Un sentido rudimentario de la equidad, una tendencia a favorecer una división igualitaria de los recursos.

4.- Un sentido rudimentario de la justicia, un deseo de ver recompensadas las buenas acciones y castigadas las malas (véase Bloom, 2013: 5 y para los experimentos que apoyan estas afirmaciones los capítulos 2 y 3 ).

Parece que podemos concluir, entonces, que ciertas bases morales no se adquieren a través del aprendizaje, sino que son el producto de la evolución biológica (Bloom, 2013: 8). A este nivel la psicología experimental habría venido a revalidar las observaciones de filósofos como Adam Smith y Thomas Jefferson, a los que Bloom cita. En cuanto a Adam Smith son muy significativas las palabras con las que comienza su Teoría de los sentimientos morales: 
Por más egoísta que se pueda suponer al hombre, existen evidentemente en su naturaleza algunos principios que le hacen interesarse por la suerte de los otros, y hacen que la felicidad de éstos le resulte necesaria, aunque no derive de ella nada más que el placer de contemplarla. Tal es el caso de la lástima o la compasión, la emoción que sentimos ante la desgracia ajena cuando la vemos o cuando nos la hacen concebir de forma muy vívida. El que sentimos pena por las penas de otros es una cuestión de hecho tan obvia que no requiere demostración alguna, porque este sentimiento, como todas las otras pasiones originales de la naturaleza humana, no se halla en absoluto circunscrito a las personas más virtuosas y humanitarias, aunque ellas quizás puedan experimentarlo con una sensibilidad más profunda. Pero no se halla desprovisto de él totalmente ni el mayor malhechor ni el más brutal violador de las leyes de la sociedad. (Smith, 1997: 49)

Por su parte, Jefferson afirmó en la Carta a Peter Carr de 10 de agosto de 1787:

El hombre fue destinado a la sociedad. Su moralidad debía por eso adecuarse a tal objetivo. Fue dotado con un sentido del bien y el mal meramente relativo a ello. Este sentido forma parte de su naturaleza tanto como el sentido del oído, el de la vista y el del tacto; es el verdadero fundamento de la moralidad, [...] El sentido moral o conciencia forma parte de un hombre tanto como su pierna o brazo. Se concede a todos los seres humanos en un grado mayor o menor, tal como cualquier miembro específico del cuerpo puede ser más fuerte o más débil. Puede ser fortalecido por el ejercicio, como cualquier miembro particular del cuerpo (Jefferson, 2014: 375-376).

Pues bien, ¿y si en Mencio y en Hume se encontrara algo muy parecido? En Hume no nos sorprendería en absoluto, pues su amistad y afinidad filosófica con Adam Smith es bien conocida ${ }^{1}$; pero ¿y en Mencio, un filósofo tan alejado en

1 Véase a este respecto Rasmussen 2017, especialmente el capítulo 5, «Theorizing the Moral Sentiments». 
siglos y en trasfondo cultural? Aquí las coincidencias son bien sorprendentes, y puede que nos digan que hemos encontrado algo importante acerca del origen de la moral.

\section{La filosofía de Confucio con la que se encuentra Mencio}

Si queremos exponer las ideas de Mencio tenemos que empezar subrayando que era un seguidor de Confucio, lo que a su vez nos obliga a decir algo, aunque sea brevemente, sobre este pensador. De momento sólo nos cabe confiar en que al final el lector quede convencido de que este desvío ha sido necesario, igual que la mención a los resultados de la psicología que expone Bloom. Comencemos pues con Confucio.

A Confucio se le puede denominar con justicia el primer filósofo de la cultura china. Vivió en un período de luchas y enfrentamientos generalizados, y en este contexto se dio cuenta de que se necesitaba una reforma radical del gobierno que permitiera salir del caos del momento; y a su vez dentro de su planteamiento de reforma política propuso una teoría moral. Pensó que todos los hombres debían intentar autoperfeccionarse mediante el estudio y la adquisición de un conjunto de virtudes. La más importante de dichas virtudes es rén, que podemos traducir al castellano como «humanidad», «bondad» o «benevolencia»². Lo más esencial de esta virtud se encuentra en la respuesta de Confucio a Zhònggong: «no hacer a otros lo que no quieras que te hagan a ti» ${ }^{3}$. Palabras que se repiten en otra ocasión:

\footnotetext{
2 Su carácter chino está compuesto de "hombre" y "dos”. En el Glosario inglés-chino que acompaña a una traducción de la obra de Mencio se define a la "benevolencia” (rén) como la virtud que consiste en tener compasión por otros y actuar de acuerdo con ello. (Menzi, 2008: 199).

3 Analectas, XII, 2 (p. 79 de la edición de Joaquín Pérez Arroyo). Las Analectas es la obra en la que se recogen los pensamientos de Confucio. Citaremos siempre el libro y el capítulo correspondiente; a lo que añadiremos la página de la edición por la que estemos citando. Obviamente no disponemos de espacio aquí para justificar en cada caso los motivos de nuestra elección de una u otra traducción. En cuanto al contenido de esta máxima de que lo que no quieras para ti no se lo hagas a los demás, hay una anécdota especialmente llamativa. Con la muerte del gran oficial de Qi, Chen Ziju, fallecido tras una enfermedad en un principado extranjero, su viuda y su intendente decidieron inmolar sirvientes para que pudieran cuidar
} 
Zìgòng preguntó: «chay alguna palabra que pueda servir de guía de conducta hasta el fin de la vida?» Confucio respondió: «Es quizás la palabra shù. Lo que no quieras que te hagan a ti no se lo hagas tú a los otros» ${ }^{4}$.

Tenemos, entonces, que el método de la benevolencia es shì, nuestra capacidad para tomarnos como medida o como analogía para adivinar los deseos de los demás. Pero, justamente porque shù es un método para adivinar lo que debemos hacer en cada situación, no puede constituir la totalidad del sentido de humanidad o benevolencia. Ha de complementarse con zhöng, nuestra capacidad para realizar lo que hemos encontrado gracias a la aplicación de shù. Por eso, en un determinado momento Confucio manifestó que su doctrina tenía un único fundamento, algo que un discípulo aclaró de la siguiente manera: «La doctrina del maestro sólo consiste en los principios del shù (compasión) y del zhōng (esfuerzo bienintencionado) $»^{5}$.

Ahora bien, siempre podemos preguntarnos, ¿por qué hemos de ser benevolentes con los demás? En suma, ¿por qué hemos de ayudarles o mostrarnos compasivos? Pregunta tanto más pertinente cuanto es fácil darse cuenta de que

de su salud. Las víctimas habían sido ya seleccionadas cuando el hermano menor de Chen, Zikang, discípulo de Confucio, llegó para la ceremonia. Informado del proyecto, Zikang halló un hábil argumento para que éste fuera detenido sin mostrar autoridad: "De ordinario es contrario a los ritos inmolar hombres en una tumba. Pero ya que la enfermedad del difunto exige cuidados particulares, ¿quién mejor que su dulce esposa y su atento intendente pueden cumplir con la tarea? Si consideráis que podemos renunciar a esta idea, estoy dispuesto a escucharos; pero si consideráis que es indispensable, entonces quisiera que seáis vosotros quienes le sirváis en el otro mundo." Citado por Levi, 2005: 39-40.

4 Analectas, XV, 24 (p. 135 de la traducción de D. C. Lau). Hay que observar que en la traducción de Joaquín Pérez Arroyo este texto aparece como XV, 23. Una parte importante de lo que viene a continuación lo hemos desarrollado (en el contexto de una comparación con el pensamiento de Aristóteles) en López Sastre, G. (1997: 279-281).

5 El texto corresponde a Analectas, IV, 15. Hemos escogido como traducción la que presenta Jesús Mosterín (Mosterín, 1983: 117). En la traducción de Pérez Arroyo se vierte como "la doctrina del maestro sólo consiste en ser fieles y en perdonar a los demás" (p. 24 de su edición), con lo que en mi opinión se pierde el sentido filosófico de lo que Confucio quiere mantener en este capítulo, que de acuerdo con James Legge se ha considerado el más profundo de toda la obra (Confucius, 1971:169, nota 15). Por el contrario, la traducción de Lau (página 74 de su edición) creo que captura muy bien el original chino. Lo vierte al inglés como "The way of the Master consists in doing one's best and in using oneself as a measure to gauge others. That is all." 
muchas veces actuar de forma benevolente puede ir en contra de nuestros intereses personales.

En las Analectas se encuentran dos respuestas diferentes a esta pregunta. En primer lugar, hay textos que parecen indicar que lo único que debe motivarnos a ser benevolentes (es decir, a comportarnos moralmente) es la moralidad misma, independientemente de toda consideración de éxito o fracaso, beneficio o resultados negativos. A este respecto podemos destacar el siguiente pasaje: "Confucio dijo: El hombre superior está centrado en la justicia, el hombre vulgar en el beneficio» ${ }^{6}$. O, en otra ocasión, una persona le preguntó a Zîlù si Confucio era aquél que continúa trabajando para un fin sobre cuya realización sabe que no hay esperanza ${ }^{7}$. Son estos textos los que nos permitirían sugerir las semejanzas entre Confucio y Kant, y afirmar que la ética confuciana es claramente deontológica. Pero, por otra parte, también nos encontramos pasajes como el siguiente:

Zîzhang preguntó a Confucio acerca de la benevolencia. Confucio le dijo: «Si eres capaz de poner en práctica cinco cosas, serás considerado benevolente en todo el ancho espacio bajo el Cielo». Zîzhang le rogó que le dijera en qué consistían estas cinco cosas, y Confucio le respondió: "Cortesía, generosidad, sinceridad, diligencia y amabilidad. Si eres cortés no te insultarán, si eres generoso te ganarás a todos, si eres sincero los demás te darán su confianza, si eres diligente conseguirás muchas cosas y si eres amable tendrás lo que hace falta para dar encargos a las demás personas» ${ }^{8}$.

\footnotetext{
6 Analectas, IV, 16 (p. 24 de la edición de Pérez Arroyo).

7 Véase Analectas, XIV, 38 (p. 130 de la edición de Lau). En la traducción de Pérez Arroyo aparece como "Ese es el que, aun sabiendo que nada se puede hacer, lo hace a pesar de todo"; y se presenta como XIV, 41.

8 Analectas, XVII, 6 (p. 122 de la edición de Pérez Arroyo). Este texto desmonta la interpretación de Jean Levi cuando afirma que "Confucio vivía en un mundo heroico en donde todas las acciones eran gratuitas. Encontraban en su belleza formal, que señalaba su cumplimiento moral, su propia justificación y su propia recompensa. Rechazaba todo compromiso; en ningún caso se trataba de ganarse a alguien con esta clase de razonamientos: "Sed buenos y os traerá cuenta'. Discurso de tendero, discurso de hombre vulgar, no de hombre honesto." (Levi, 2005: 195).
} 
Citar esta reflexión de Confucio es muy importante porque demuestra que la benevolencia no es desinteresada, sino que tiene que ver con el beneficio mutuo, con los resultados que se obtienen con su ejercicio. Interpretación que se ve confirmada por este otro pasaje: ofensa?"

1. Alguien dijo a Confucio: «¿Qué pensáis de la devolución de virtud por

2. Confucio contestó: «¡Y con qué pagaríais entonces la virtud?»

3. «A la ofensa se contesta con justicia y a la virtud con virtud», concluyó el Maestro»?.

En resumen, lo que aparece aquí es una ética teleológica, atenta a lo que se consigue con nuestras acciones, y en donde shù debería traducirse como «reciprocidad", pues el motivo para el obrar moral se encuentra en el beneficio, en el resultado que piensa obtenerse con la acción dentro del marco de una especie de acuerdo o pacto social. En suma, estaríamos ante una estrategia de cooperación. Según esta interpretación, y como escribió Max Weber, «el confucianismo es más racionalista y serio, en el sentido de la ausencia y el rechazo de toda suerte de criterios no utilitarios, que cualquier otro sistema ético, con la posible excepción del de J. Bentham» ${ }^{10}$.

Que en Confucio encontremos dos respuestas tan diferentes (una en la que parece que la moralidad se basa en sí misma y otra en la que se recurre al criterio de utilidad, a los resultados que se obtienen con nuestro comportamiento) puede explicarse por varias razones. En primer lugar, hay que destacar el hecho de que Confucio no escribió nada. Sus Analectas constituyen en realidad una colección

\footnotetext{
9 Analectas, XIV, 36 (p. 102 de Pérez Arroyo). Hay que observar que en la traducción de Lau aparece como XIV, 34. Por el contrario, en la obra taoísta más importante, el Lao zi se dirá: "responde a la injusticia con la virtud." Lao zi 1986: 53 (XXVI; LXIII en las ediciones anteriores al descubrimiento de los textos de Ma wang dui). También es interesante comparar la respuesta de Confucio con la afirmación de Jesús: "Amad a vuestros enemigos, haced el bien a los que os odian, bendecid a los que os maldicen, rezad por los que os injurian. Al que te pegue en una mejilla, preséntale la otra" (Lucas, 6, 27 y sigs.). Esta última comparación se encuentra en Ching, J. y Küng, H., 1991:145.

10 Citado por Creel, 1976: 52-53. Bien es verdad que hemos visto que en las Analectas no se rechazan "toda suerte de criterios no utilitarios". En la historia de la filosofía china el debate sobre la posibilidad o deseabilidad de una ética utilitaria es extremadamente importante. Dentro de un momento vamos a ver cómo se posiciona Mencio al respecto.
} 
bastante heterogénea de dichos y anécdotas compiladas mucho después de su muerte por discípulos de discípulos. Además, la impresión que se obtiene de su lectura es que lo importante para Confucio era la comunicación oral con un interlocutor o con una audiencia particular, que son los que determinaban el sentido de unas palabras que buscaban ante todo educar y mejorar a sus oyentes. En última instancia, transformarlos. Lo determinante a tal efecto era el efecto de las palabras, su papel en cambiar a aquél que las escuchaba. En terminología actual, diríamos que la pragmática era más importante que la semántica. Un texto es muy significativo a este respecto: «Fracasar en hablar con el hombre que es capaz de obtener beneficio de nuestras palabras es dejar que el hombre se desperdicie. Hablar con un hombre que es incapaz de beneficiarse es dejar que las palabras se pierdan. Un hombre sabio no dejará que se pierdan ni los hombres ni las palabras ${ }^{11}$. Y está claro que personas distintas necesitaban mensajes distintos. La capacidad y preparación previa del interlocutor no podían, por tanto, perderse nunca de vista. En este momento fundacional de la filosofía china no importó tanto obtener una expresión rigurosa y precisa, elaborar una teoría consistente, cuanto lograr una extraordinaria capacidad de sugerencia que pusiera en juego las capacidades interpretativas del lector (o de la audiencia), y le obligara a adoptar un papel activo -no de mero receptor de una idea- y a embarcarse en un verdadero esfuerzo de autoconocimiento. Algo que implicaba abstenerse de la articulación plena de un pensamiento, y que se conseguía mediante la presentación de aforismos, anécdotas y poesías ${ }^{12}$. Nada podría estar más lejos del afán de sistematicidad que se encuentra en Aristóteles y que requiere la presencia de un hilo discursivo y de un importante énfasis en la argumentación, lo que en la tradición occidental ha justificado la elaboración de una prosa que acaba constituyendo el tratado filosófico. Tampoco debiéramos sorprendernos tanto. Igual que hay un cambio de Heráclito y Parménides a Aristóteles, en el caso del mundo chino el discurso de Mencio será mucho más elaborado que el de Confucio. Han aparecido otras escuelas que cuestionaban los principios de ese primer maestro, y Mencio siente la necesidad de argumentar más y mejor. La filosofía se ha convertido en disputa y Mencio actúa en consecuencia. El momento de la sistematicidad ha llegado. Un conocido estudioso del pensamiento chino al que ya hemos mencionado, Jean Levi, observa:

\footnotetext{
11 Analectas, XV, 8 (p. 133 de la traducción de Lau. Aunque en nuestra versión al castellano hemos modificado algo su traducción. Por lo demás, en la traducción de Pérez Arroyo el texto aparece como XV, 7).

12 Véase a este respecto Fung, 1987: 39-44; y Lai, 2008: 16-17. Por supuesto, generalizaciones de este tipo, aunque sin duda son inevitables y útiles, han de tomarse con cautela.
} 
La retórica en Mencio no es un arma afilada al servicio de la bondad, sino que, al contrario, la bondad es un arma de su retórica. Mencio es un sofista y su discurso suena falso; no es que sea un cínico, pero como todos los oportunistas se adhiere plenamente a las ideas que le benefician. Su discurso suena a hueco, pues no se puede promulgar una teoría de la sinceridad absoluta, de la bondad y de la misericordia y, al mismo tiempo, usar armas de mala fe para hacer prevalecer la sinceridad absoluta, la bondad y la misericordia. De hecho, él mismo se ve obligado a reconocer que se sitúa en el terreno del adversario. Cuando uno de sus detractores le reprocha ser un amante de la disputa, se defiende replicando que, si cede a la polémica, es porque no tiene más remedio (Levi, 2005: 193).

La exageración de la tesis la hace poco convincente. Considerar a Mencio como un sofista y un oportunista nos parece absurdo; pero en las afirmaciones de Levi hay un destello de verdad. Mencio sabe que tiene que argumentar y disputar.

\section{El planteamiento de Mencio}

De hecho, el libro de Mencio comienza con una historia en donde se rechaza explícitamente la apelación al beneficio, una de las dos posibles fuentes de la moral para Confucio. Mencio sabe que tiene que posicionarse con claridad desde el principio:

1. Cuando Mencio apareció ante Huì, rey de Liáng, éste le dijo: «El venerable no ha considerado que mil lis [el $l i$ era una antigua unidad de medida china equivalente a casi quinientos metros] son una gran distancia para venir, porque tal vez hay en ello beneficio para mi reino».

2. Mencio respondió: «¿Por qué su majestad habla de beneficio, cuando también existen el amor a los hombres y la rectitud?» 
3. «Si el rey se pregunta ¿Cómo puedo beneficiar mi reino? Los grandes señores se preguntarán ¿Cómo puedo beneficiar mi casa? Los caballeros y los plebeyos se preguntarán ¿Cómo puedo beneficiarme a mí mismo? Los superiores y los inferiores lucharán por el beneficio y el reino peligrará» ${ }^{13}$.

Ahora mismo no nos interesa detenernos en si este razonamiento resulta o no acertado. De hecho, podría pensarse que en tanto que el argumento indica que atender al beneficio (es decir, a la utilidad) resulta a la larga poco beneficioso, en realidad parece constituir un argumento utilitarista, dando por aceptado aquello mismo que pretende rechazar. Pero lo importante es que Mencio piensa que ha refutado una posible base de la moral, la que apela al beneficio, y por lo tanto cree que tiene que buscar otra. Por los motivos que sea tampoco le convence la primera propuesta de Confucio, que podría resumirse en que el hombre verdaderamente benevolente no se pregunta por qué ha de ser benevolente; y en este contexto Mencio va a acudir como respuesta a hablar de la naturaleza humana. La misma va a aparecer como la base que fundamenta la moral. Ser moral va a ser una forma de ser humano. Esto es lo que necesita explicar, y para ello recurre a dos ejemplos que expresa con gran elegancia literaria.

El primero es el siguiente: preguntado por un rey sobre si sería capaz de ser un verdadero rey y proteger a su pueblo, Mencio contesta que sí, y que su certeza se basa en esta historia. Sabe que un día el rey vio pasar a una persona conduciendo a un buey. Iba a sacrificarlo para consagrar una campana con su sangre. El rey ordenó que se liberara al buey, porque no soportaba «su aspecto asustado, como el de un inocente que se aproxima al lugar de su ejecución». Pero en este caso, le preguntaron, ¿quedará sin consagrar la campana? De ninguna manera, respondió el rey, se reemplazará al buey por un cordero. Uno puede preguntarse si hemos avanzado en algo. Si el rey se dolía del buey que era conducido al sacrificio, ¿por qué no dolerse del cordero al que le espera el mismo fin? Mencio contesta que la clave está en que el rey había visto al buey, pero no al cordero, y continúa: «la actitud del hombre superior en su relación con los animales es ésta: si los ha visto vivos,

13 Mencio 1, A, 1. A partir de ahora citaremos el libro de Mencio como Mencio, seguido del número del libro, de una letra (A o B) que indicará la parte del mismo, y de un número que indicará el capítulo. Igual que en el caso de Confucio utilizaremos distintas traducciones, eligiendo la que nos parezca más acertada, que denominaremos por el nombre del traductor. En este caso hemos citado la de Pérez Arroyo, que aparece en la página 147 de su edición de Los cuatro libros. 
no puede soportar verlos morir; y una vez que ha oído sus sonidos de agonía no puede soportar comer su carne. Eso es por lo que el hombre superior se mantiene a distancia de las cocinas» ${ }^{14}$. A uno se le ocurre pensar en la conocida expresión: "Ojos que no ven, corazón que no siente», y esto es verdad. Justamente por ello este sentimiento de piedad o compasión sólo es el punto de partida de la moral. De hecho, Mencio quiere que el rey comprenda que, una vez que tiene ese sentimiento, necesita extenderlo, desplegarlo de una manera consistente; algo de lo que hablaremos dentro de un momento. En todo caso, el rey tiene que darse cuenta de que, si su bondad alcanza a los animales, los beneficios de su gobierno deben llegar a todo el pueblo. La moralidad, en efecto, no admite excepciones. Pero, claro, antes de extender el sentimiento de forma reflexiva tenemos que poseerlo.

Mencio vuelve a insistir en la importancia de este sentimiento cuando afirma: «Todos los hombres tienen un corazón incapaz de soportar los sufrimientos de los otros», y pone otro ejemplo. El de alguien que viera que un niño está a punto de caer a un pozo. ¿No experimentaría una reacción de espanto? El aprestarse a ayudarle sería algo inmediato, que no tendría nada que ver con la motivación de obtener el agradecimiento de los padres ni fama entre sus conocidos. Luego podemos concluir, piensa Mencio, que quien está desprovisto de compasión, de la capacidad de simpatizar con los demás, no es verdaderamente humano ${ }^{15}$. Y a este nivel es muy interesante comparar el ejemplo de Mencio con las ideas que Rousseau manifiesta. Este escribe en su Discurso sobre el origen y los fundamentos de la desigualdad entre los hombres:

Con placer vemos al autor de la Fábula de las abejas, forzado a reconocer al hombre como un ser compasivo y sensible, salir, en el ejemplo que de ello nos da, de su estilo frío y sutil, para ofrecernos la patética imagen de un hombre encerrado que percibe fuera a una bestia feroz arrancando del regazo de su madre a un niño, destrozando bajo su dentadura asesina los débiles miembros y desgarrando con sus uñas las entrañas palpitantes de ese niño. ¡Qué horrible agitación no experimenta ese testigo de un suceso en el que ningún interés personal tiene! ¡Qué angustias no sufre ante esta visión por

4 Véase Mencio, 1, A, 7. Me baso en la versión de Lau, p. 55 de su edición.

15 Véase Mencio, 2, A, 6. 
no poder llevar ningún socorro a la madre desvanecida ni al hijo moribundo! (Rousseau, $1985: 236-237)^{16}$

Tenemos (esto es lo que probarían los ejemplos) que la base de nuestros juicios morales son sentimientos como la simpatía y la compasión. La moral comienza con el hecho bruto de que el dolor, el sufrimiento que encuentro a mi alrededor, no me resulta ajeno, sino que me conmueve. Mencio habría insistido hace ya muchos siglos en que es aquí que debemos situar si no (obviamente) toda la moral, sí el germen de la misma. De hecho, la expresión que Mencio utiliza (duan) hace referencia al brote de una planta en cuanto surge del suelo. Otro germen, otro brote de la moral, sería el de la rectitud. Aquí el ejemplo es el siguiente:

Si entre las cosas que el hombre ama, la vida fuese la primera, nada haría entonces que la pusiera en peligro. Si entre las cosas que el hombre detesta, la muerte fuese la primera, lo haría todo para evitar cualquier peligro. / Hay ocasiones, sin embargo, en que el hombre puede conservar la vida haciendo algo determinado y no lo hace, o en que pudiendo evitar la muerte por medio de una determinada conducta no la evita. /... Supongamos que la vida depende de una cesta y de un plato de sopa; si los conseguimos viviremos y, si no, moriremos. Si son ofrecidos con insultos, ni un caminante necesitado los aceptaría; si se los pisotea antes de darlos, ni un mendigo se cuidaría de recogerlos (Mencio 6, A, 10, pp. 274-275 de la edición de Pérez Arroyo).

\footnotetext{
16 Debo la comparación entre Mencio y Rousseau al excelente libro de F. Jullien, Fundar la moral. Diálogo de Mencio con un filósofo de la Ilustración (Jullien, 1997: 25-26); y véase para todo lo anterior López Sastre, G. (2007: 52-53). Hablando de esa reacción espontánea e inmediata ante un niño que está a punto de caerse a un pozo descrita por Mencio, Jullien escribe que "no podemos suponer que sea el producto de alguna interiorización: ni del resentimiento de los débiles (como en Nietzsche), ni de un interés de clase (como en Marx), ni de la función del Padre (como en Freud). Es ideológicamente pura, libre de toda alienación. También puede servir como piedra de toque de la moral" (Jullien, 1997: 46). Nosotros diríamos que es completamente natural, corresponde a esa empatía y compasión que Paul Bloom ha demostrado convincentemente que poseen hasta los niños muy pequeños.
} 
Al fin y al cabo, podríamos preguntarnos: ¿no nos convence íntimamente la expresión «vale más morir de pie que vivir de rodillas»? Aquí estaría actuando el sentido de la rectitud o de la dignidad. Pues bien, admitiendo que un corazón que simpatiza (con un animal a punto de ser sacrificado o con un niño a punto de caerse a un pozo) tiene el brote emergente de la benevolencia; y que quien es consciente de la vergüenza (como nuestro mendigo que sin embargo no acepta una comida ofrecida de una forma indigna), posee el de la rectitud ${ }^{17}$; admitiendo esto, insisto, que tenemos esos brotes igual que tenemos miembros como brazos o piernas, ¿qué necesitamos para que se desarrollen? Mencio piensa en un proceso educativo pero que en cierta medida es espontáneo, análogo a como un fuego puede extenderse de forma natural ${ }^{18}$. Dos comparaciones nos iluminan a este respecto (llegados a este punto ya debiéramos estar convencidos de lo pedagógico que pretende ser Mencio).

Frente a un filósofo que afirmaba que la naturaleza humana es como un sauce y la rectitud como un cuenco o una taza, y que por lo tanto convertir a la naturaleza humana en benevolente y recta es como hacer cuencos y tazas a partir del sauce, Mencio va a replicar que los cuencos y las tazas no se hacen siguiendo la naturaleza del sauce, sino dañándole o mutilándole. Si aceptáramos esta analogía habríamos de concluir que para producir la benevolencia y la rectitud tenemos que dañar la naturaleza humana, con lo que esa producción no sería sino una desgracia. Nada más lejos de la realidad. Los actos bondadosos son un producto natural de la naturaleza humana. Algo que se entiende cuando el mismo filósofo utiliza otra analogía que Mencio va a utilizar a su manera: «La naturaleza humana es como una corriente de agua que fluye rápidamente; si se abre un boquete al Este correrá hacia el Este, si se le abre un boquete al Oeste correrá hacia el Oeste. La naturaleza del hombre no distingue entre el bien y el mal, de la misma manera que el agua no distingue entre el Este y el Oeste». Pero la respuesta de Mencio es que es verdad que el agua no distingue entre el Este y el Oeste, ¿pero tampoco distingue entre arriba y abajo? Igual que el agua de forma natural tiende hacia abajo la naturaleza humana tiende al bien. Si golpeamos al agua podemos hacerla ir hacia arriba, por encima de nuestra cabeza, ¿pero es esa la naturaleza del agua? No, actúa así en función de la circunstancia

17 Véase Mencio 6 A 6. En un estudio introductorio al pensamiento de Voltaire encuentro la siguiente cita de este autor: «Está probado que la naturaleza nos inspira por sí sola ideas útiles que preceden a todas nuestras reflexiones. Todos tenemos dos sentimientos que son el fundamento de la sociedad: la conmiseración y la justicia» (Aramayo 2015: 78-79).

18 Véase para este tema Graham, 1989: 126-127. 
de nuestro golpe o palmoteo. Aquí la naturaleza humana no sería diferente a la del agua: la naturaleza humana es buena, esta es su dirección natural, aunque las circunstancias pueden hacer que una persona actúe mal o se vuelva malvada ${ }^{19}$. Y aquí Mencio vuelve a proponernos otra comparación. Se habla de los bellos árboles que hubo una vez en una montaña, pero como esta montańa estaba muy cerca de un sitio muy poblado las hachas acabaron con ellos (imaginemos que para hacer leña). Gracias a las lluvias y a la humedad del rocío salieron brotes y tallos, pero el ganado se los comió. El resultado es una montaña pelada. Al verla así, la gente no cree que allí hubo árboles alguna vez. Pero nosotros podemos preguntarnos, ¿es esa la naturaleza de la montańa? Si no se hubiera visto alterada por nuestra actuación los árboles la hubieran cubierto de forma natural. Pues bien, pensemos ahora en los seres humanos. ¿Es que les falta en su corazón benevolencia y rectitud? La forma en que los pierden es como se abaten los árboles por la actuación del hacha. El resultado es que a veces vemos un animal (un hombre malvado) y pensamos que allí no había ninguna capacidad. Está claro que nos equivocamos tanto como los que desconocen que en la montańa había árboles ${ }^{20}$.

En otro texto, Mencio es más concreto a la hora de buscar responsabilidades, pues afirma que sólo un verdadero caballero (un hombre moral superior) es capaz de tener un corazón perseverante cuando carece de medios de subsistencia. La mayor parte de las personas, si de manera cotidiana no disponen de recursos, carecerán también de un corazón perseverante, y así no evitarán el mal. Pero -y aquí Mencio se muestra como un autor verdaderamente moderno- castigarlos porque hayan caído en el delito cuando este es el producto de las circunstancias, ¿no es como ponerles una trampa? ¿Es algo que haría una persona benevolente que ocupara un puesto de responsabilidad? ${ }^{21}$ Parece claro que la responsabilidad de un gobernante sería garantizar la satisfacción de las necesidades básicas de su pueblo, evitando de esta forma que las personas cayeran en la senda del mal. Aunque hay que observar que Mencio es consciente de que las cosas no son tan sencillas, algo que podemos comprender si atendemos a una pregunta. Vale que el pueblo se haya corrompido y vuelto inmoral por su situación de pobreza, pero ¿y los gobernantes? ¿Cómo es que ellos se han corrompido previamente? ¿Cómo es que no han desarrollado los gérmenes de la benevolencia y la rectitud si podemos imaginar que esos gobernantes han disfrutado de recursos

19 Véase para esas comparaciones Mencio 6 A 1 y 6 A 2.

20 Véase Mencio 6 A 8.

21 Véase Mencio 1 A 7, hacia el final del capítulo. 
y condiciones económicas favorables? ¿De dónde ha surgido el egoísmo que los convierte en malos gobernantes y que hace que se despreocupen del bienestar de la población? Y si en ellos parece que hay un enemigo interno de su potencial para la bondad, ¿cómo podríamos estar seguros de que en el caso del pueblo bastan condiciones económicas satisfactorias para asegurar su bondad? ¿No habrá igualmente en el pueblo -es decir, en todos nosotros- un principio interno lo suficientemente poderoso para en muchos casos bloquear el desarrollo moral? ${ }^{22}$ Pero no nos interesa ocuparnos ahora mismo de este problema, que es verdad que plantea una pregunta que puede poner en cuestión toda la arquitectura del proyecto de Mencio; por eso vamos a volver a lo que de momento nos importaba, ¿Cómo desarrollar la naturaleza humana? Si por una parte están las circunstancias exteriores, que pueden ser más o menos favorables, por otro lado, está el propio esfuerzo, porque a este nivel el punto de partida es idéntico para todos. Si nos diferenciamos es en función de esas influencias externas y de nuestro propio esfuerzo:

1. Mencio dijo: en los años de abundancia, la mayoría de los jóvenes son gentiles, en los años de escasez, la mayoría de los jóvenes son violentos. Esta diferencia no se debe al potencial que el Cielo les ha conferido, sino a que las circunstancias ahogan su corazón. Tomemos el ejemplo de la cebada: esparcimos la semilla y la cubrimos de tierra. Tenemos el mismo suelo y el tiempo de siembra es el mismo. Las semillas germinan y cuando llega su tiempo todas las plantas están maduras. Si hay diferencias será porque el suelo era más o menos fértil, porque las lluvias y rocíos las alimentaron de forma diferente y porque el esfuerzo humano no fue igual en todas ellas. Por consiguiente, si todas las cosas del mismo tipo se parecen, ¿por qué se duda de esto solamente cuando llegamos al hombre? Los grandes sabios y nosotros somos de la misma especie (Mencio 6 A 7 $)^{23}$.

22 Para el problema en Mencio de este principio interno que conduce al mal y una posible solución véase Schwartz, 1985: 268-275. La toma de conciencia de que tiene que haber algún principio interno del mal hace que no podamos estar de acuerdo sin más con la afirmación de la estudiosa Anne Cheng de que Mencio se dispensa de plantear frontalmente la cuestión del mal (Cheng, 2002: 156), otra cosa es el grado en el que se reconozca la gravedad del problema.

23 Pero compárese la traducción de Lau (164), en donde la diferencia entre dos circunstancias (años de abundancia y años de escasez) tienen un efecto diferente, pero en ambos casos corruptor de la naturaleza humana: en un caso los hombres se vuelven perezosos (no "gentiles" o "excelentes"; como traducen Van Norden, p. 150, y Pérez Arroyo, pp. 271-272; que son en las que me baso) y en el otro, violentos. 
Igual que un campesino puede dedicar más cuidados a unas plantas que a otras, cada uno de nosotros puede obrar de la misma manera con relación a su interior. El hecho cierto es que nuestra naturaleza hay que cultivarla. Desde luego, no hay que esforzarse de tal forma que se la destruya. No debiéramos ser como el hombre de Sòng, que preocupado porque sus brotes no crecían lo suficiente tiró de ellos hacía arriba con el resultado de que se desenraizaron y se marchitaron ${ }^{24}$. Pero tampoco vale no hacer nada. Mencio se decanta así por un gradualismo, por una postura en donde se va avanzando poco a poco. El mecanismo de ese avance es la extensión ${ }^{25}$. Se trata de que partiendo de que hay muchas cosas que no podemos soportar, aprendamos a no soportar otras ${ }^{26}$. De acuerdo con el ejemplo que hemos visto, se trata de que el rey, una vez que se ha hecho consciente de la preocupación que tiene por el buey, la extienda a sus súbditos. Y esto es importante, porque también existe la alternativa de sofocar el sentimiento en vez de cultivarlo. Puestos a poner ejemplos, uno del siglo XX puede servirnos muy bien. Se trata del caso de una mujer que vivía próxima al campo de Mauthausen y que vio gente fusilada que sobrevivió varias horas antes de morir. Ante esta experiencia escribió para protestar: «A menudo le toca a uno ser testigo involuntario de tales atrocidades. Estoy en todo caso asqueada, y semejante espectáculo me pone tan nerviosa que a largo plazo no puedo soportarlo. Pido que se ordene poner fin a esos actos inhumanos, o bien que se realicen donde nadie los vea» (Glover, 2013: 517). Esta persona tenía capacidad de empatía, lo que la permitía considerar ese espectáculo como una atrocidad, como un acto inhumano que la ponía de los nervios. Una solución (podríamos decir la compasiva) era proponer terminar con esos fusilamientos. Pero otra solución (no compasiva) que planteaba era que ese sufrimiento se alejara de ella. Simplemente no quería verlo ${ }^{27}$. Desde el punto de vista de Mencio esta última opción no sería humana, sino que nos situaría al nivel de los animales. Nuestra diferencia con los mismos es pequeña, y hay muchas personas (los hombres vulgares) que la abandonan, pero, por el contrario, los hombres superiores la preservan ${ }^{28}$. No hacerlo es perder lo mejor de

\footnotetext{
24 Véase Mencio 2 A 2.
}

25 Desde una perspectiva actual el tema está muy bien expuesto en el capítulo 5, "Try, but Not Too Hard” de Singerland, 2014.

26 Véase Mencio, 7 B 31.

27 Igual que Mencio advertía que quien quisiera disfrutar de una comida era mejor que no viera la ejecución de los animales que va a consumir.

28 Véase Mencio 4 B 19. Esto habría que matizarlo a la luz de nuestros conocimientos actuales sobre el comportamiento de los monos capuchinos y los chimpancés. A este respecto puede consultarse el interesantísimo libro de Frans De Waal Primates y filósofos. La evolución moral del 
nuestra identidad humana, enfermar. Por eso, estudiando a Mencio, Jullien puede escribir que:

[..] mostrarse humano, como debe ser, es hacer efectivo a mi alrededor esta sensibilidad hacia los otros -que es virtual en mí. Los comentaristas ulteriores no encontrarán nada mejor que caracterizar este sentido de lo humano que ilustrándolo en relación con el cuerpo. En los tratados médicos chinos, el mismo término de ren (compuesto por el hombre y el número dos) sirve para designar, empleado de manera negativa, el entumecimiento de la extremidad de los miembros, manos o pies. Como la energía vital «ya no pasa a través de ellos», ya no se los siente. Estar no-ren es estar entumecido. Por el contrario, estar ren, mostrarse humano, es sacar la conciencia del entumecimiento en relación con los otros, estar receptivo a lo que les sucede, sentir reforzado el vínculo vital con ellos ${ }^{29}$.

Pues bien, esa receptividad hacia los otros hay que cultivarla y, como decía, extenderla. Mencio sugiere empezar con lo próximo. Podemos empezar, dirá, por tratar bien a nuestros familiares mayores y luego extender ese comportamiento a los mayores de otras familias; o tratar bien a nuestros hijos para luego tratar también bien a los hijos de los demás ${ }^{30}$. Sobre la interpretación precisa de este proceso de extensión se ha discutido mucho ${ }^{31}$. Para nosotros, lo importante es que puede necesitar de la imaginación y de la razón. De la imaginación, porque la extensión del sentimiento requerirá muchas veces que imaginemos similitudes que quizá a primera vista no se perciban, como cuando observamos -por ejemplo, gracias a Shakespeare- que personas de otro color de piel, de otra religión o de otras culturas poseen sin embargo nuestra misma capacidad para el placer o el dolor. De la razón, porque muchas veces esta modulará el sentimiento al estar atenta a los resultados de nuestras acciones. Sin duda nos compadecemos de nuestro hijo pequeño cuando le van a realizar un análisis de sangre y oímos sus gritos y vemos su resistencia a que le claven la aguja; pero este sentimiento no debiera evitar que le realicen tal análisis. Nuestra razón nos dice que se trata de un mal necesario que debemos asumir. Aquí el valor moral no está en la reacción

simio al hombre, en donde el pensamiento de Mencio está bien presente (Véase De Waal, 2007: 77-80).

29 Jullien, 1997: 92-93.

30 Véase Mencio 1 A 7. Recomendamos para este pasaje la traducción de Lau (pp. 56-57), mientras que la de Pérez Arroyo (pp. 153-154) no recoge para nada el sentido de lo que estamos manteniendo.

31 Véanse las palabras de Bryan W. Van Norden en Menzi 2008: 12. 
inmediata, sino en seguir el dictado de la razón que nos habla de la conveniencia de la prueba. Ahora bien, no tendríamos ningún motivo para asumir las molestias de la misma si no fuera el caso que queremos a nuestro hijo, que tenemos un sentimiento que nos vincula con él; y -de hecho- es ese sentimiento el que hace penosa la observación de su dolor y su angustia. $Y$ aprovechando esas reflexiones generales quizá haya llegado el momento de adentrarnos en la teoría moral de Hume.

\section{La teoría moral de Hume}

David Hume observa en la sección 1, titulada «De los principios generales de la moral», de su Investigación sobre los principios de la moral que hay una discusión que se refiere al fundamento general de la moral: ¿se deriva de la razón o del sentimiento? ¿ «obtenemos su conocimiento mediante una cadena de argumentos o inducciones, o por un sentimiento inmediato»? Establecido así el marco del debate, Hume va a proponer a sus lectores que hay un sentimiento que la naturaleza ha hecho universal en toda la especie: «Uno puede aventurarse a afirmar que no hay criatura humana a la que la aparición de la felicidad cuando no hay lugar para la envidia o la venganza- no proporcione placer, y la aparición de la desdicha, incomodidad. Esto parece inseparable de nuestra estructura y constitución» ${ }^{32}$. Cuando no ocurre esto, cuando la felicidad de los demás no despierta nuestra aprobación y su desgracia nuestra compasión, no estaríamos ante un ser humano, sino ante lo que Hume denomina un «monstruo imaginario»:

Supongamos que una persona está constituida originariamente de tal forma que no tiene ninguna preocupación por sus semejantes, sino que considera la felicidad y el sufrimiento de todos los seres sensibles con una indiferencia más grande que a dos tonalidades colindantes del mismo color.

32 Hume, 1991, sección VI, 102-103, nota a pie de página. Hume hablará de sentimiento de benevolencia, de humanidad, o de simpatía. Véase Hume, 199, Apéndice II, 172, nota a pie de página. 
Supongamos que, si se colocara a un lado la prosperidad de las naciones y al otro su ruina, y se le pidiera que escogiera, que permaneciera como el asno del escolástico, indeciso y sin determinarse entre dos motivos iguales; o, más bien, de forma parecida al mismo asno colocado entre dos trozos de madera o de mármol, sin ninguna inclinación ni propensión hacia ningún lado. Creo que habría que admitir que tal persona, al estar completamente despreocupada del bien público de la comunidad o de la utilidad privada de otras personas, miraría a todas las cualidades, por perniciosas o beneficiosas que fueran para la sociedad o para su poseedor, con la misma indiferencia que al objeto más común y falto de interés (Hume, 1991, sección VI, 103).

Por utilizar el ejemplo de Mencio, quien no se sintiera afectado por el niño que está a punto de caerse al pozo para Hume no sería humano, sería un monstruo; o quizá pudiéramos decirlo de otra forma, estaría enfermo. Le faltaría lo que Hume denomina el sentimiento de humanidad. Y aquí nos gustaría insistir en que esta no es una alternativa frente a la que tenga que defenderse el teórico de la moral, porque es bastante fácil concluir -decíamos hace un momento- que esa persona, al tener rotos sus vínculos con los sentimientos de los demás, al no verse afectada por los mismos, está psicológicamente muy enferma. Estaríamos ante un psicópata, una figura todo menos envidiable, más susceptible de provocar pena u horror que otra cosa33. Eso sí, nos muestra de dónde parte la moral, de que nos vemos afectados por la felicidad o la infelicidad de los demás. La moralidad tiene su base, entonces, en el hecho bruto de que «en nuestro pecho se ha infundido cierta benevolencia, por pequeña que sea» (Hume, 1991, Sección IX, Conclusión, 143). La coincidencia con Mencio es muy llamativa ${ }^{34}$. Para Hume el punto de partida de la moral es que existen «ciertos instintos implantados de manera originaria en nuestra naturaleza», y va a mencionar la benevolencia y el resentimiento, el amor a la vida, la amabilidad hacia los nińos, el deseo general del bien y la aversión hacia el mal (Hume, 1978, II, III, III, 417). De forma natural experimentamos un deseo de que quienes nos rodean sean felices, y este sentimiento hace que el bienestar de los demás se convierta en cierta medida en nuestro propio bienestar (por supuesto, siempre que no haya contraposición de

\footnotetext{
33 Véase para esto el capítulo titulado «El hombre amoral» (pp. 17-26) de la Introducción a la ética de Bernard Williams (Williams, 1987).

34 Para una comparación detallada entre el pensamiento de Mencio y el de Hume puede acudirse al libro Mencius, Hume and the Foundations of Ethics de Xiusheng Liu.
} 
intereses), lo que provoca que lo persigamos por los motivos combinados de la benevolencia y el disfrute propio ${ }^{35}$.

Ahora bien, Hume es muy consciente de que como cuestión de hecho simpatizamos más con las personas que nos están próximas que con las que nos quedan lejos, más con los conocidos que con los extraños, más con nuestros compatriotas que con los extranjeros. Pero esta es una realidad psicológica que no debe condicionar los juicios morales. Estos se elaboran desde un punto de vista general, no particular. Aunque muchas veces no consigamos alterar nuestros sentimientos, sí podemos cambiar nuestro lenguaje. Con un ejemplo que pone Hume en su Tratado de la naturaleza humana:

Nuestro sirviente, si es diligente y fiel, puede despertar sentimientos más fuertes de amor y ternura que Marco Bruto, tal como nos lo representa la historia; pero no decimos en base a esto que el carácter del primero sea más laudable que el del último. Sabemos que, si nos aproximásemos a la misma distancia al renombrado patriota, nos exigiría un grado mucho mayor de afecto y admiración. Tales correcciones son comunes con respecto a todos los sentidos, y de hecho sería imposible que pudiésemos hacer uso del lenguaje o comunicarnos nuestros sentimientos si no corrigiésemos la apariencia momentánea de las cosas y pasáramos por alto nuestra situación presente (Hume, 1978, III, II, I, 582).

Luego la imaginación interviene en la moral permitiéndonos viajar en el tiempo y en el espacio para buscar un punto de vista privilegiado, uno que es más general que el de nuestra situación particular. Y por supuesto también la razón interviene en los juicios morales. Podríamos simpatizar en un primer momento con la liberalidad de un príncipe que hace un regalo u organiza un gran banquete, pero si luego nos enteramos de que el precio de ese regalo ha sido el pan cotidiano de muchos trabajadores lo normal es que desaparezcan nuestras alabanzas, y que incluso el propio sentimiento de complacencia desaparezca para ser sustituido por uno de disgusto ${ }^{36}$. Esto nos recuerda mucho a Mencio; por una parte, a la idea de que hay que extender el sentimiento, que si no se extiende

35 Véase para esto Hume, 1991, Apéndice II, 176.

36 Véase Hume, 1991, II, 44-45. Allí hay también otros ejemplos en los que opera la razón. Para un análisis de la corrección de la simpatía con vistas a lograr un punto de vista moral véase Baillie, 2000: 189-199. 
puede quedarse en un mero germen, en un mero brote que todavía no es moral, como el rey que se preocupaba del buey pero no de sus súbditos; y luego a la idea de que esta extensión se consigue gracias al diálogo, al intercambio de ideas entre el rey y Mencio, al uso del razonamiento por analogía por parte de este (algo así como ¿por qué no preocuparse de los hombres si estos también, igual que el buey, pueden sufrir?). Es así como se produce la elaboración de un lenguaje moral que nunca debe olvidar que tuvo su origen en experiencias inmediatas que están en nuestra naturaleza - para volver a Paul Bloom, con quien comenzábamos- ya desde nuestra infancia más temprana.

\section{Bibliografía}

Aramayo, R. R. (2015). Voltaire. la ironía contra el fanatismo. Barcelona: Batiscafo.

Baillie, J. (2000). Hume on Morality. London: Routledge.

Bloom, P. (2013). Just Babies. The Origins of Good and Evil. New York: Broadway Books.

Confucio, Mencio (i982). Los cuatro libros, Madrid: Alfaguara. Prólogo, traducción y notas de Joaquín Pérez Arroyo.

Confucius (1971). Confucian Analects. The Great Learning and The Doctrine of the Mean. New York: Dover. Translated, with Critical and Exegetical Notes, Prolegomena, Copious Indexes, and Dictionary of All Characters By James Legge.

(1979). The Analects. Harmondsworth: Penguin. Translated with an Introduction by D. C. Lau.

Creel, H. G. (1976). El pensamiento chino desde Confucio hasta Mao Tse-Tung. Madrid: Alianza. Traducción de Salustiano Masó Simón.

Cheng, A. (2002). Historia del pensamiento chino. Barcelona: Bellaterra. Traducción de Anne-Hélêne Suárez Girard.

Ching, J. y Küng, H. (I99I). Christianisme et religion chinoise. París: Ed. du Seuil.

De WaAl, F. (2007). Primates y filósofos. La evolución de la moral del simio al hombre. Barcelona: Paidós. Traducción de Vanesa Casanova Fernández.

Fung, Yu-Lan (1987). Breve historia de la filosofía china. México: Fondo de Cultura Económica. Traducción de Juan José Utrilla. 
Glover, J. (2013). Humanidad e inhumanidad. Una historia moral del siglo XX. Madrid: Cátedra. Traducción de Marco Aurelio Galmarini.

Graham, A. C. (1989). Disputers of the Tao. Philosophical Argument in Ancient China. La Salle: Open Court.

Hume, D. (1978). A Treatise of Human Nature. Oxford: Oxford University Press. Edited by L. A. Selby-Bigge, 2nd ed. with text revised by P. H. Nidditch.

(1991). Investigación sobre los principios de la moral. Madrid: Espasa Calpe. Introducción, traducción y notas de Gerardo López Sastre.

JefFerson, T. (2014). Escritos politicos. Madrid: Tecnos. Edición y estudio preliminar de Jaime de Salas. Traducción de Antonio Escohotado y Manuel Sáenz de Heredia.

Jullien, F. (1997). Fundar la moral. Diálogo de Mencio con un filósofo de la Ilustración. Madrid: Taurus. Traducción de Héctor Subirats y Silvia Kiczkovsky.

LaI, K. L. (2008). An Introduction to Chinese Philosophy. Cambridge: Cambridge University Press.

LaO Zi (1986). Lao zi (El libro del Tao). Madrid: Alfaguara. Edición bilingüe. Traducción, prólogo y notas de Juan Ignacio Preciado.

Levi, J. (2005). Confucio. Madrid: Trotta. Traducción de Albert Galvany.

Liu Xiusheng (2003). Mencius, Hume and the Foundations of Ethics. Aldershot: Ashgate.

López SAStre, G. (1997). "Un diálogo intercultural en el mundo ético: la reflexión sobre la vida buena en Aristóteles y en Confucio", en R. Villena (coord.): Ensayos humanisticos. Homenaje al profesor Luis Lorente Toledo. Cuenca: Ediciones de la Universidad de Castilla-La Mancha, pp. 273-284.

(2007). "¿En qué reposa la moralidad? Una respuesta desde una perspectiva intercultural.", en N. Zavadivker (comp.): La ética en la encrucijada. El debate de los fundamentos de la moral. Buenos Aires: Ed. Prometeo, pp. 47-61.

Mencius (1970). Mencius. London: Penguin. Translated with an Introduction by D. C. Lau.

MenZI (2008). Menzi with selections from traditional commentaries. Indianapolis/ Cambridge: Hackett. Translated with Introduction and Notes by Bryan W. Van Norden.

Mosterín, J. (1983). Historia de la filosofia. 2. La filosofia oriental antigua, Madrid: Alianza.

Rassmussen, D. C. (2017). The Infidel and the Professor. David Hume, Adam Smith, and the Friendship that Shaped Modern Thought. Princeton: Princeton University Press.

Rousseau, Jean-Jacques (1985). Del contrato social. Discursos. Madrid: Alianza. Prólogo, traducción y notas de Mauro Armiño. 
SingerLand, E. (2014). Trying not to try. Edinburgh and London: Canongate.

Schwartz, B. I. (1985). The World of Thought in Ancient China, Cambridge, Massachusetts: Harvard University Press.

Smith, A. (1997). La teoría de los sentimientos morales. Madrid: Alianza. Versión española y estudio preliminar de Carlos Rodríguez Braun.

Williams, B. (1987). Introducción a la ética. Madrid: Cátedra. Traducción de Manuel Jiménez Redondo.

Recibido: $23 / 01 / 2018$

Aceptado: 28/03/2018

Este trabajo se encuentra bajo una licencia de Creative Commons ReconocimientoNoComercial-SinObraDerivada 4.0 
